\title{
TECHNIQUES FOR DESIGNING AND WRITING VIDEOSCRIPTS
}

\author{
Ron S. Buca
}

\begin{abstract}
Teachers of technical writing soon will need to include scenario and script writing techniques into their technical writing courses, because some engineers and technologists are already presenting their reports by videotape rather than on paper. Planning and writing the script for a video report differs markedly from planning and writing a traditional technical report. Teachers who master the techniques also can enhance the courses they teach by writing and producing educational programs using their university's or college's ETV facilities.
\end{abstract}

\section{INTRODUCTION}

Video is becoming more and more popular as a means for conveying information within technical organizations, and between organizations and their clients or the public. Videotaped reports are being used, for example, to describe construction progress of a remote hydro generating plant to shareholders at a company's annual meeting, to inform head office of the results of core analyses conducted at a remote drilling site, to summarize the results of an evaluation of highway marking paints, and to familiarize field staff with new techniques they will have to implement.

The purpose of this paper is to familiarize teachers of technical writing with the steps involved in planning, script-writing, and producing a technical videotape. The paper will describe how to develop a scenario to suit the audience and the topic, when to select a particular method of presentation (lecture, interview, narration, or drama), how to design a script, and how to write realistic narration and dialogue. It will also cover the importance of pre-production planning in developing a program that will be acceptable to the critical eyes of viewers accustomed to commercial television. 


\section{PLANNING}

Thorough planning is essential if you are to experience a smooth running production. The four parts of the planning stage comprise:

- Defining the potential audience.

- Establishing a clear objective.

- Choosing a presentation method.

- Developing a suitable scenario.

\section{Defining the Audience}

Many commercial television programs are aimed at a very large general audience who are assumed to have approximately an average grade 10 education. The writer of a technical or business videotape cannot make such a sweeping generalization, because the focus of the program will be narrower and the potential audience will be much smaller. Thus a scriptwriter must first clearly define the audience, which will be one or more of:

- the general public,

- managers and business administrators,

- engineers, scientists and computer specialists,

- technicians,

- shareholders,

- clients and customers, and

- students (secondary or post-secondary).

A scriptwriter must then ask four questions, the answers to which will establish his or her planning criteria:

1. What education level, on average, will this audience have attained?

2. Will they be knowledgeable within the discipline and know the terminology?

3. How much prior knowledge of my topic will they likely have?

4. Will they be carrying any misconceptions about my topic, which I will have to correct?

(If these seem like the questions you would ask when defining the audience for a written report, you are quite correct.) 


\section{Establishing the Objective}

The second step is to identify whether the videotape has to tell or sell. (A "tell" videotape describes a situation or reports a condition. A "sell" videotape tries to change the viewer's thinking or elicit action.) If the purpose of a program is to describe the progress of construction work at a new but remote hydro-electric power generating plant to the corporate executives, shareholders, or general public, then it will primarily tell. But if the purpose is to demonstrate that the construction work is being impeded by inadequate resources, and so convince viewers that an infusion of funds is necessary to prevent the project from drifting behind schedule, then it will have to sell.

If the objective is to tell, the scriptwriter must decide to what extent the audience is to be entertained as well as informed (because information presented in an entertaining way can help drive the message home). If the objective is to sell, then he or she must also determine whether the audience is to:

- react (i.e. draw a conclusion, make a decision, or invoke action), or

- be educated (i.e. learn a new technique, or have a previously learned technique reinforced).

\section{Choosing a Presentation Method}

Generally, a video report or "educational" program can be presented as a lecture, an interview, a narrated story, or a dramatized event.

The Lecture Method. In the 1960s videotaped lectures were mistakenly thought to be an economical way to present information to college students. Now the "talking head" is rarely used alone and even then is limited to very short segments which are frequently interspersed with cuts to illustrations. It is the least expensive method to produce but its entertainment level normally is low.

The lecture method is occasionally used in videotapes accompanying remote learning programs (correspondence courses), when the course developer or a narrator speaks directly to the learner so that he or she will feel less isolated and be encouraged to continue working on the course.

The Interview Method. In an interview, the interviewer and speaker sit across from one another and the camera cuts between them, occasionally 
showing both together in what is known as a "two shot." The interviewer asks questions that elicit responses from the speaker, and the dialogue again is interspersed with camera cuts to illustrations and film clips. The entertainment potential is only moderate, although greater than for a lecture, and the cost also is only moderate.

An interview can be used for both informative and persuasive programs. Generally only an outline script is developed so that the exchanges between interviewer and narrator appear natural. In "sell" situations the script has to be carefully orchestrated to ensure the presentation invokes the desired reaction from viewers.

The Narrated Story. Here, the narrator usually remains off screen, reading from a fully prepared script. A full story line is developed, with the camera cutting between scenes and actions, some of which may be animated or produced electronically. The narrated story is ideal for both informative and persuasive programming, and is particularly suitable when the intent is to educate. Its entertainment potential ranges from moderate to high, and so does its cost.

The Dramatized Story. This is the method that most closely parallels commercial television, and so its entertainment level is high. A storyline and characters are conceived to carry the message, and a full storyboard and script are developed from which the director and actors work. However, only limited information can be conveyed since much of the time is used to present the story. The method is most suitable for educational programs and is seldom used when the intent is purely to inform. This is the most expensive method to produce.

Which method--or combination of methods-you choose for a particular program will depend on your budget, whether your purpose is to inform or persuade, and how much you need to entertain your audience. You have to make this decision early in the planning stage, since the steps that follow depend on your selection.

\section{Developing a Scenario}

The scenario is the story line you plan to follow, and it includes the locations, scenes, people, and events which, when combined into a plot, will best convey your message to the viewers. (It should not be confused with the script, which contains the actual directions the director and cast will follow, and the exact words the narrator and actors will speak.) Developing and writing the scenario demands innovation and imagination. 
Figure 1 shows an imaginary three-level scenario developed one step at a time. As its writer devised each level, she came to terms with the limitations of the scenario she had developed to that point, recognized that she had enough money in her budget to develop a more innovative scenario, and then let her imagination soar. You can do the same when devising your own scenario: start with a basic framework, then examine it to see how you can improve it, repeating the steps until you have developed the optimum scenario for the topic within your budget, equipment, and time constraints.

\section{FIGURE 1.}

\section{EVOLUTION OF A SCENARIO.}

\section{SCENARIO: VIDEO REPORT ON RESULTS OF DRILLINO TESTS}

\section{Level 1 Saenario}

The geologist faces the camera and describes the drill core:

1. Identifies where and when core was drilled (shows map)

2 Points to core samples and identifies composition at various strata levels.

3. Describes importance and impact of findings.

During sequence, camera cuts between geologist, map, and drill core samples.

\section{Level 2 Scenario}

An off-screen narrator introduces and comments on what is seen on screen:

1. Sequence opens with a general view of drill site. Narrator (V.O.) identifies it and its location, and introduces geologist. Camera culs to map as he speaks.

2. Geologist faces camera and aplains his rationale for drilling here.

3. Cut to view of core being extracted.

4. Geologist comments on drilling depth.

5. Geologist describes composition of drill core at various strata levels, camera cutting to core and samples.

6. Narrator (V.O.) comments on importance and impact of geologiat's finding

7. Fade out on genernl view of drill site.

\section{Levet 3 Soenario}

An on-ecreen narrator speaks to viewers and interviews geologist and others:

1. Fade in on drilling site with a truck approaching. Cut to drilling operations and close in on the drill.

2. Cut to narrator and geologist, wearing hard hats and in conversation, beside the drill. Narrator tums to camers, describes where they are, and introduces geologist.

3. Narrator continues conversation with geologist, posing questions. In his replies, geologist identifies purpose of drilling program and what he hopes to achieve/learn from core analysea. Geologist shows map and camera cuts to it.

4. Cut to drill rig and core being extracted, toreman and geologist watching. Geologist discusses depth of drill with foreman, and foreman describes problems of drilling at that level. Camera cuts to cutaway drawing of earth's crust and drill hole through it.

5. Cut to narrator interviewing geologist, who comments on:

- Composition of drill core.

- Importance of his findings.

6. Camera zooms in on narrator commenting on the impact of the findings on the company.

7. Closing sequence, showing geologist watehing drill being reinserted; narrator (V.O.) offers cloaine remarts. 
The Level 1 Scenario in Figure 1 is primarily informative and makes too much use of a "talking head". It would be suitable for a short field report to management, but would be too static for other uses.

The Level 2 Scenario combines two methods: the narrated story and the lecture method. It, too, is primarily informative, but is presented in a moderately more entertaining way. It would be suitable for presenting information to management, shareholders, and possibly the public.

In the Level 3 Scenario the scriptwriter has combined elements of the narrated story and the interview method. The interviews are carried out informally at the job site, as though the people taking part normally would be there, are involved with the events, and are naturally conversing with each other. Hence, the realism is greater and the interest level is higher. This scenario could be both informative and persuasive, and would be suitable for presenting to shareholders, the public, and to students.

Conceivably there could have been a Level 4 Scenario written as a Dramatized Story, but for the topic being described and the likely purpose of the videotape, such a treatment would have been unnecessarily expensive. The scriptwriter was correct to stop when she did.

Storyboarding is a particularly useful component of scenario development, because it can help both the scriptwriter and the production crew perceive how the final production will look. In storyboarding, you draw rough sketches of certain scenes you plan to videotape, and place them beside the physical descriptions of the sets and events.

\section{WRITING THE VIDEOSCRIPT}

\section{Videoscript Appearance}

A videoscript is prepared in two columns, one for video (what the viewer will see), and one for audio (what the viewer will hear). The video column is on the left and may be narrower than the audio column, with typical column widths on an $8 \frac{1}{2}$ inch wide page being 3 inches and 4 inches. There are no. set rules for typing the script, some people saying that it should be double-spaced throughout and others recommending that directions and instructions be in lower case letters and dialogue in capital letters. The following conventions work well, and were used to develop the segment of script in Figure 2: 
- All dialogue is typed double-space in a mix of upper- and lowercase letters.

- Names of speakers, and directions for emphasis and inflection that are embedded in the dialogue, are typed in capital letters.

- All camera, set, and movement instructions are typed single space in capital letters.

As a scriptwriter you are entitled to adopt whatever convention you find most comfortable to work with. Ideally you should also consult a book on scriptwriting, such as William Van Nostran's The Nonbroadcast Television Writer's Handbook ${ }^{1}$.

\section{Learning the Terminology}

Your script will seem much more professional, and the video crew will love you more, if you use terminology they are accustomed to. For example:

CUT TO means make an immediate transition from one scene to the next, without fading out the first and then fading in the next.

DISSOLVE means make a slow transition from one scene to the next so that the scenes overlap as one is faded out and the other is faded in.

FADE IN and FADE OUT apply to both video and audio. They tell the editor to introduce or remove the picture or sound gradually.

FADE TO BLACK means fade the picture gradually to a blank screen.

PAN LEFT or PAN RIGHT means to move the camera slowly from left to right or right to left.

SUPERIMPOSE means to superimpose one scene directly on top of another, so both are visible. This is done most often with titles, with the letters appearing superimposed over the action.

VOICE OVER means the person speaking is not visible.

ZOOM IN or OUT means to use the zoom lens to close in on or pull out from the scene. 


\section{FIGURE 2.}

\section{EXCERPT FROM A VIDEOSCRIPT.}

\section{WEEKASKASING FALLS VIDEO REPORT - PAGE 3 \\ VIDEO}

CUT TO: L.S. OF MULLEN APPROACHING; WALKS BESIDE POWER PLANT, UNDER CONSTRUCTION. HE WEARS HARD HAT, CARRIES CLIPBOARD.

MULLEN STOPS, LOOKS AROUND, MAKES A NOTE.

HE TURNS IN TOWARD WALL, STOPS AT BASE AND PEERS UP. SHADES EYES WTTH HAND.

CUT TO: TOP OF WALL. TWO WORKERS LAY BRICKS.

(CUT TO SPEAKERS, AS APPROPRIATE)

MULLEN STARTS TO WALK AWAY.

CUT TO: INIERIOR OF INSTRUMENT LAB, LS. MULLEN ENTERS THROUGH WEST DOOR.

\begin{abstract}
AUDIO
NARRATOR: (V.O.) Ciff Mullen is chiet engineer at Weekaskasing Falls ...

He's been here three years... Saw the cats dig the first hole, not far from where he is now ...

MULLEN: (SHOUTS) is Barry Wilson up there?

WORKER: (LOOKS BEHIND WALL, CALLĩ) Hey, Barry! Chief wants you.

WILSON: (LOOKS OVER WALL \& DOWN) Oh! Hi, chief.

MULLEN: (CALLING) Will you be through here Friday?

WiLsON: Thursday, more likety.

MULLEN: Well done!

NARRATOR: (V.O.) Exterior work at Weekaskasing Falls is 11 daye ahead of schedule... Inside, the
\end{abstract}

If you plan to tell the director the type of shot you want for a particular scene, you will also need to know that:

C.U. means "close up,"

M.S. means "medium shot," and

L.S. means "long shot."

\section{Writing the "Front Matter"}

At the front of the script you should describe the people and sets appearing in the videotape and provide any other details the production crew will find useful, such as:

- The purpose of the videotape and what it is intended to achieve.

- A summary of the main action (the story line). 
- A description of each person who will be appearing on camera, which will be either a real description if a person is appearing as him or herself (the geologist, for example), or a character description if you will be using actors or employees who will be "role playing." For example:

$$
\begin{aligned}
& \text { Jill -- Department Head. About } 40 . \\
& \text { Knowledgeable, direct, confident, } \\
& \text { decisive, persuasive. }
\end{aligned}
$$

- A description of each set or location you will be using to videotape the action. For example:

Meeting Room -- Uncluttered boardroom with a print on each wall. Large table suitable for six people to sit around it. Six semi-executive chairs.

Drill Site -- Location shots at Penrose Mine, Alberta, with drilling rig in operation.

- Sketches of maps, charts, illustrations, seating plans, etc, that will be integrated into the script.

\section{Writing Narration}

A narrator's role is to draw viewers' attention to significant occurrences on camera, and to comment on their impact or importance. For example, if the camera is to be recording a geologist and crew chief examining a core as it is withdrawn from a drill head, with the geologist making notes on a pad, a report writer might write this for the off-screen narrator to say:

NARRATOR: (V.O.) To build a profile of strata at different levels, as each core reaches the head the geologist checks with the drilling crew chief to identify at what level it was excavated.

But such a statement would sound wooden, and would appeal only to a limited range of viewers, mostly technical. A better script would include dialogue:

GEOLOGIST: Looks like a good sample.

CREW CHIEF: Yeah. No fractures. 
GEOLOGIST: What level?

CREW CHIEF: Six hundred and seventy-two feet.

NARRATOR: (V.O.) From data like this, the geologist builds a profile of soil and rock at different levels.

A narrator has to "chat" to viewers, so his or her language must never be formal. To help the narrator deliver a fluid, comfortable commentary, use contractions such as "I'll," "doesn't," and "won't" rather than "I will," "does not," and "will not." And replace large words like "anticipate" and "remuneration" with simple words like "expect" and "pay." For example, instead of writing:

NARRATOR: (V.O.) It will take another four weeks before the drilling can be completed.

Write:

NARRATOR: (V.O.) It'll take four weeks to finish the drilling.

\section{Writing Dialogue}

Some people have an "ear" for writing good dialogue, just as some people have an ear for writing and playing music. And there are others for whom it is a real chore. Yet dialogue is an excellent way to build a natural conversational tone into a video production. Here are three techniques to help you write good dialogue:

- First write a history--a background--for each character for whom you have to write dialogue. You need to know what makes the character "tick," and in particular what pleases, irritates, challenges, annoys, and "drives" him or her. You need to know your characters well enough so that you can tell almost intuitively how they will react to a particular situation, and what they will say. (Many playwrights claim that their characters frequently take charge of their own actions and sometimes have to be reined in to keep the script going in the way the author intended!)

- Second, practice writing dialogue 10 to 15 minutes every day. Think of two people in a given situation, give each a name, and then let them begin discussing any topic they feel like talking about. 
- And, third, say the words out loud as you write them, and again each time you read them. Hearing the dialogue will help you differentiate between conversation that sounds natural and realistic, and conversation that sounds stilted.

In real life people seldom speak in nicely formed sentences; they tend to talk in fragments. Compare this dull, pedantic conversation with the more natural example on page 38:

GEOLOGIST: That looks like a good sample.

CREW CHIEF: Yes, it does. It has no fractures.

GEOLOGISTS: From what level did you take it?

CREW CHIEF: Six hundred and seventy-two feet.

\section{Writing Interviews}

You cannot really write the dialogue of an interview; you can only provide the "shell" that will shape it. The shell should spell out the questions the interviewer will ask, and sometimes provide comments on what the person being interviewed should supply in his or her reply. For example:

INTERVIEWER: (Asks what the geologist will do with the data he is accumulating.)

GEOLOGIST: (Describes how he will develop a profile and what he hopes the profile will show.)

(The brackets show that the statements are only "shells.")

\section{TAKING PART IN THE PRODUCTION}

Although the production stage promises to be the most exciting part of making a television report (it's not as easy to be enthusiastic about planning and writing), scriptwriters often find they have little to do. And because television production, like film-making, is a slow, time-consuming, fragmented activity, scriptwriters often become frustrated because they cannot see the program that they conceived and wrote growing into a contiguous whole. Yet they need to be there, partly so they can make on-the-spot script 
amendments as they are needed, and partly to monitor how closely the production crew has understood the scriptwriter's concept and is translating it into the production.

\section{Maintaining an Unobtrusive Presence}

As a scriptwriter you should be present for all of the auditioning, at some of the rehearsals, and throughout the video-taping. The ideal place to be, during both auditions and production, is the control room. Here you can watch the events on a television monitor and see them just as a viewer will see them. The worst place is on the set, for there you will be influenced by the flurry of activity, which will blind you to the limited picture the viewer will eventually see.

\section{Reviewing the Final Product}

The scriptwriter is seldom involved with the editing, which is fortunate because it is a lengthy, time-consuming task. When it is complete, the production crew will ask you to review the videotape in its near-final form. There are, however, limitations to any change you can. request:

- Unlike film, videotape cannot be cut and spliced, which means you cannot insert additional sequences, remove unwanted sequences, or shorten or lengthen sequences.

- All changes have to be made electronically. If you wish to make a change, the new material must exactly fit the space occupied by the material it has to replace.

If you can arrange it, also have a number of additional people who had nothing to do with the production preview the videotape. Discuss their and your comments with the production crew, and then jointly decide whether any changes should be incorporated.

\section{CONCLUSIONS}

A well-made video production has the potential for creating far greater impact on viewers than a written report on the same subject is likely to have on readers. Yet for all its "glamour" image, planning, writing, and producing a video report, instruction, or teaching aid is very hard work. For those who choose to become involved, the task is always challenging, often frustrating, and surprisingly rewarding. I can recommend it! 


\section{REFERENCE}

1. William Van Nostran, The Nonbroadcast Television Writer's Handbook (White Plains, NY: Knowledge Industry Publications, Inc., 1983).

Ron Blicq is Head, Technology Communication Department, Red River Community College, Winnipeg. 